\title{
Laboratory Scale Electrostatically Assisted Wet Scrubber for Controlling Dust IN LIVESTOCK BUILDINGS
}

\author{
E. A. Almuhanna, R. G. Maghirang, J. P. Murphy, L. E. Erickson
}

\begin{abstract}
A prototype electrostatically assisted particulate wet scrubber (EPWS) for controlling dust in livestock buildings was developed and tested under laboratory and field conditions. Under laboratory conditions, the EPWS with the negatively-charged water spray had significantly higher particle removal efficiency (79\%) than either the uncharged wet scrubber (58\%) or the control (i.e., only the fan was operated; $21 \%$ ). There was no significant difference in removal efficiency between the negatively-charged EPWS (79\%) and the positively-charged EPWS (73\%). For the negatively-charged EPWS, an optimum ratio between the air flow rate and amount of water spray for each specific mixing volume existed in which the removal efficiency decreased as the air flow rate increased. Field tests in a swine building proved that the EPWS was effective in removing airborne dust.
\end{abstract}

Keywords. Indoor air quality, Dust control, Charged water spray, Electrostatic force.

$\mathrm{P}$ revious studies have shown that dust along with viable microorganisms, fungi, and adsorbed gases in livestock buildings contribute to the increased incidence of respiratory disorders among livestock workers (Dosman et al., 1988; Donham et al., 1989; Zejda et al., 1993, 1994; Senthilselvan et al., 1997a). In addition, reducing airborne dust concentration in buildings has resulted in improvement in human respiratory responses (Senthilselvan et al., 1997b; Zhang et al., 1998).

Air quality in livestock buildings should be improved to prevent potential occupational health problems. Engineering control strategies include the following: (1) reducing generation rates of the air contaminants or source control strategies, including use of feed additives (fat or oil), cleaning of dusty surfaces, and spraying water or oil over dusty surfaces; (2) dilution and/or effective room air distribution or ventilation control strategies, including increased ventilation rate, purge ventilation, and effective room air distribution system; and (3) air cleaning or removal control techniques, including ionizers, wet scrubbers, or other air cleaners.

A wet scrubber uses a scrubbing liquid (e.g., water) to remove pollutants, including dust particles and gaseous pollutants, from gas streams. Dust particles are captured by

Submitted for review in September 2008 as manuscript number SE 7695; approved for publication by the Structures \& Environment Division of ASABE in June 2009.

The authors are Emad A. Almuhanna, ASABE Member Engineer, Assistant Professor, Department of Agricultural Systems Engineering, King Faisal University, Hofuf, Saudi Arabia; Ronaldo G. Maghirang, ASABE Member Engineer, Professor, James P. Murphy, ASABE Fellow, Professor, Department of Biological and Agricultural Engineering, Kansas State University, Manhattan, Kansas; and Larry E. Erickson, Professor, Department of Chemical Engineering, Kansas State University, Manhattan, Kansas. Corresponding author: Emad A. Almuhanna, Department of Agricultural Systems Engineering, King Faisal University, Hofuf, Saudi Arabia; phone: 966-5-05923428; fax: 966-3-5800404; e-mail: ealmuhanna@kfu.edu.sa. liquid droplets via the following major collection mechanisms: inertial impaction, interception, and diffusion. Inertial impaction and interception are usually highly efficient for particles larger than $10 \mu \mathrm{m}$; whereas, diffusion is the dominant collection mechanism for particles less than approximately $0.3 \mu \mathrm{m}$ (Hinds, 1999). Inertial impaction occurs when a particle, because of its inertia, is unable to adjust quickly enough to the abruptly changing streamlines in the vicinity of a liquid droplet and crosses the streamlines to hit the droplet. Interception occurs when a particle is offset slightly from directly impacting a liquid droplet but, because of its finite size, strikes and is collected by the droplet. Collection by diffusion occurs when small particles, because of the random Brownian motion, happen to diffuse toward and are collected by the droplet. In some cases, electrostatics has been used to augment particle removal efficiency of water droplets (Lear et al., 1975; Hassler and Birgitta, 1978). In these scrubbers electrical forces are introduced by imposing electrostatic charges onto the water droplets before they enter the inlet of wet scrubbers. By charging the water droplets, the electrostatic attraction between the particles and the water droplets will be enhanced, resulting in increased particle removal efficiency. In addition to particle removal, wet scrubbing can be used to remove water-soluble gases, including ammonia and odorous compounds. Licht and Miner (1979) found a highly significant relationship between odor removal and particle removal by scrubbers.

Recent research has indicated the potential of electrostatically charged water spray in reducing dust concentration in enclosed spaces under controlled laboratory conditions (Almuhanna et al., 2008). In the said research, they aerosolized test particles (i.e., corn starch and sodium bicarbonate) into a closed experimental chamber. Charged water droplets were then sprayed into the chamber. An Aerodynamic Particle Sizer ${ }^{\text {TM }}$ (APS) spectrometer was used to measure the particle concentration and size distribution. In addition, a tapered element oscillating microbalance (TEOM) was used to measure the mass concentration. From 
the APS and TEOM data, the particle removal efficiency of the charged water spray was determined. In general, the electrostatically charged water spray proved to be effective in reducing airborne dust concentration in the chamber under controlled laboratory conditions.

As an extension of the above project, this study was conducted to develop and evaluate a prototype electrostatically assisted particulate wet scrubber (EPWS) for dust control in livestock buildings. The scrubber was evaluated under controlled laboratory conditions and also in a swine building.

\section{Materials ANd Methods Description of the Prototype EPWS}

Figure 1 is a schematic diagram of the prototype EPWS. It consisted of the following components: (1) axial fan, (2) mixing chamber, (3) charged water spraying system, (4) air outlet, and (5) air inlet. The top and bottom sides of the $0.17-\mathrm{m}^{3}$ mixing chamber were covered with sheet metal for grounding purposes. The $31-\mathrm{cm}$ diameter axial fan provided variable volumetric of up to $27 \mathrm{~m}^{3} / \mathrm{min}(953 \mathrm{cfm})$. The fan was mounted in a fiberglass duct and its motor speed was controlled by a voltage controller. Figure 2 shows the relationship between the fan setting and scrubber air velocity. The air velocity within the scrubber was measured at various traverse points at the scrubber inlet and outlet cross-sections

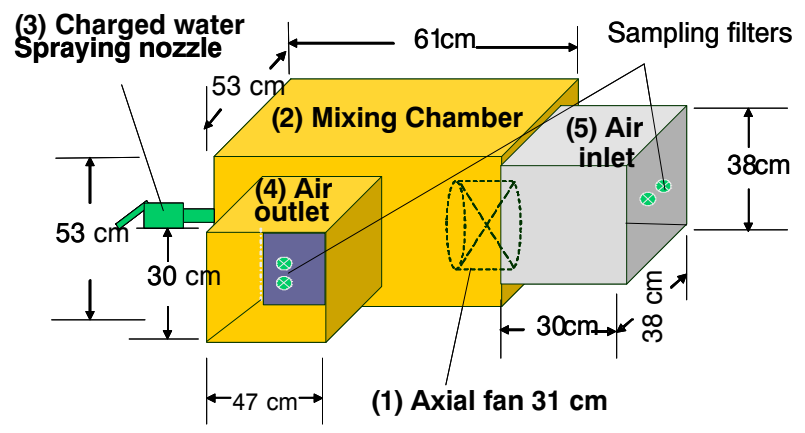

Figure 1. Schematic diagram of the prototype electrostatically assisted particulate wet scrubber (EPWS) (not drawn to scale).

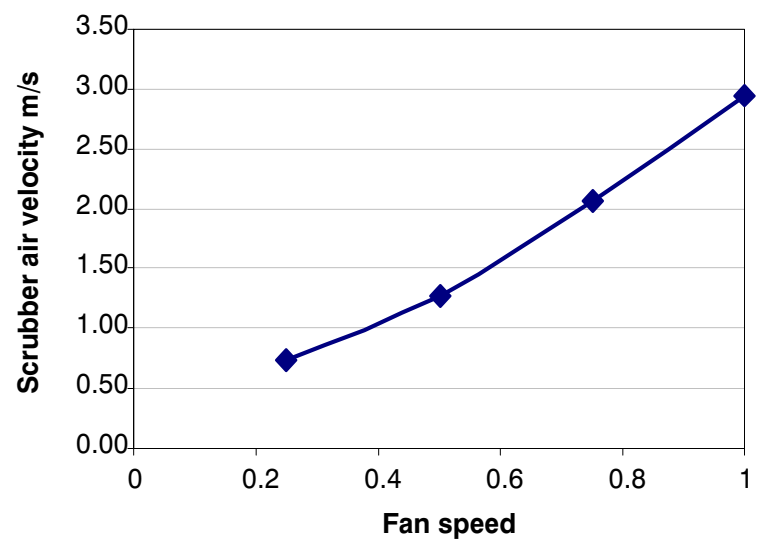

Figure 2. Relationship between scrubber average air velocity and normalized fan speed. using a hot-film anemometer (model 8347, TSI Incorporated, Shoreview, Minn.).

Charged water spray was generated using a commercially available electrostatic water spraying device (ESS XT, Electrostatic Spraying Systems, Inc., Watkinsville, Ga.) developed for agricultural chemicals application (Law, 1978, 2001). The spraying nozzle was positioned on the side of the mixing chamber facing the fan outlet. The spraying direction was facing the air stream. In this study, the spraying system was operated at a liquid flow rate of $120 \mathrm{~mL} / \mathrm{min}$ [at a water tank pressure of $103 \mathrm{kPa}(15 \mathrm{psi})$ ]. The droplets range in size from about 25 to about $60 \mu \mathrm{m}$ as stated by the manufacturer (Electrostatic Spraying Systems, Inc., Watkinsville, Ga.). Measurement with a cascade impactor (model 110, MSP Corporation, Shoreview, Minn.) showed that the charged water spray had a mean geometric mean diameter (GMD) of $21 \mu \mathrm{m}$ and a geometric standard deviation (GSD) of 1.8. The mean net charge-to-mass ratios of the charged droplets were $-6.5 \mathrm{mC} / \mathrm{kg}\left(\mathrm{SD}=0.9 \mathrm{mC} \mathrm{kg}{ }^{-1}\right)$ for the negatively-charged EPWS and $+7.2 \mathrm{mC} / \mathrm{kg}(\mathrm{SD}=1.6 \mathrm{mC} \mathrm{kg}-1)$ for the positively-charged EPWS (Almuhanna et al., 2008). The electrostatic charge was measured with a dynamic Faraday cage sampler (Almuhanna, 2007), which was designed in accordance with the ASTM guidelines (ASTM Standards, 1997) and can be used to measure the net charge-to-mass ratio of particles. Table 1 summarizes the charge measurement for the air that was coming out from the scrubber outlet. It can be seen that considerable amount of charge was generated with the EPWS.

Dust was collected inside the EPWS and drained outside the scrubber via a drain hole in the bottom of the scrubber and was then collected in a waste tank.

\section{LABORATORY EVALUATION}

The EPWS was first tested under controlled laboratory conditions to establish the effects of scrubber air flow rate (i.e., 6.4, 11, 18, and $25 \mathrm{~m}^{3} / \mathrm{min}$ ), grounding the chamber walls, charge polarity (negative vs. positive), and type of test particle (i.e., corn starch and $\mathrm{NaHCO}_{3}$ ) on its performance. It was also compared to the case in which the scrubber was operated with uncharged water (i.e., uncharged scrubber) and that in which only the fan (i.e., no water spray) was operated. The case in which only the fan was operated served as the control. Corn starch and $\mathrm{NaHCO}_{3}$ were selected as the test particles based on safety and size distribution. Table 2 summarizes the particle size distribution of the particles, as measured with the APS.

Table 1. Charge measurement for the air for the air exiting the scrubber.

\begin{tabular}{ccc}
\hline Scrubber Fan & Spray Nozzle & Charge $(\mathrm{nC})^{[\mathrm{a}]}$ \\
\hline OFF & OFF & +0.13 \\
\hline ON & OFF & +0.16 \\
& Air only without charging & +0.38 \\
& Air only with charging (negative) & -0.41 \\
& Water spray without charging & +0.15 \\
& Water spray with charging (negative) & -114 \\
\hline
\end{tabular}

[a] Measurements were made using a dynamic Faraday cage sampler with a sampling duration of one minute (Almuhanna, 2007) at a distance of $1 \mathrm{~m}$ from the scrubber outlet. 
Table 2. Statistics of the initial particle size distributions (mass basis) of dispersed corn starch and $\mathrm{NaHCO}_{3}$.

\begin{tabular}{lcccccc}
\hline & \multicolumn{2}{c}{ Corn Starch } & & \multicolumn{2}{c}{$\mathrm{NaHCO}_{3}$} \\
\cline { 2 - 3 } Parameter & Mean & $\mathrm{SD}$ & & Mean & $\mathrm{SD}$ \\
\hline Median diameter $(\mu \mathrm{m})$ & 14.1 & 0.41 & & 7.61 & 0.88 \\
Mean diameter $(\mu \mathrm{m})$ & 13.6 & 0.39 & & 7.85 & 0.68 \\
Geometric mean diameter, GMD $(\mu \mathrm{m})$ & 13.1 & 0.50 & & 6.14 & 0.53 \\
Geometric standard deviation, GSD & 1.37 & 0.04 & & 2.22 & 0.04 \\
\hline
\end{tabular}

Whereas results with these particles may not be the same as with typical dust in livestock buildings, they will provide an indication of the relative effectiveness of the EPWS. All experiments were conducted in an experimental chamber (fig. 3) in which air temperature and relative humidity were maintained at approximately $25^{\circ} \mathrm{C}$ and $40 \%$, respectively. For each experiment the chamber was prepared by cleaning the surfaces and running its air filtration system. There was no ventilation of the chamber during the experiment.

Particles were dispersed into the chamber by using a pressurized canister at $652 \mathrm{kPa}(80 \mathrm{psig})$. A nominal mass of $20 \mathrm{~g}$ was used; the actual mass deployed ranged from 7.4 to $12.5 \mathrm{~g}$ for corn starch and from 2.7 to $8.3 \mathrm{~g}$ for $\mathrm{NaHCO}_{3}$. Dispersion took approximately $2 \mathrm{~s}$. To further disperse the particles inside the chamber, two mixing fans inside the chamber were operated for about 2 min after deployment of the particles. The scrubber fan and the water spray were operated starting at $\mathrm{t}=2 \mathrm{~min}$ (i.e., $2 \mathrm{~min}$ after particle deployment). At $\mathrm{t}=3 \mathrm{~min}$ the sampling pump for the filter samplers (described later in this section) was operated for 2 min. Again, for the control, only the fan was turned on; the water spray was not used.

For all cases, air sampling was done under isokinetic conditions at two locations within the inlet and outlet ducts of the EPWS. The filter samplers had 11-mm probe inlet diameter and 37-mm filter assembly (fig. 4). The sampling heads were positioned within the sampling area facing the air stream. The filter holder was attached to a rigid tube, which was connected by flexible tubing to a vacuum pump. The air sampling flow rate was adjusted to isokinetic conditions by varying the sampling flow rate to match the air velocity at the inlet area of the sampler with the air stream velocity outside the sampler. The required sampling flow rates for isokinetic sampling (table 3 ) were determined by conducting a velocity traverse over the sampling area prior to sampling (Predicala and Maghirang, 2004). The dust collection filters (Type AE,

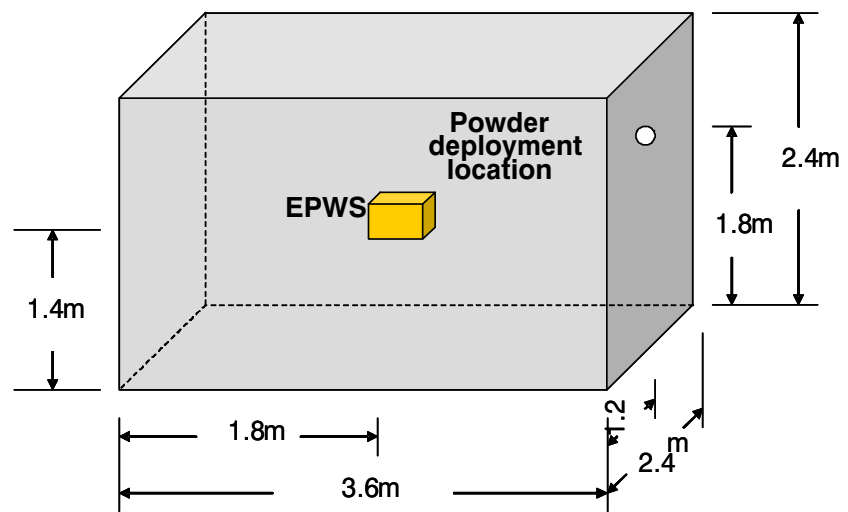

Figure 3. Schematic diagram of the experimental chamber (not drawn to scale).

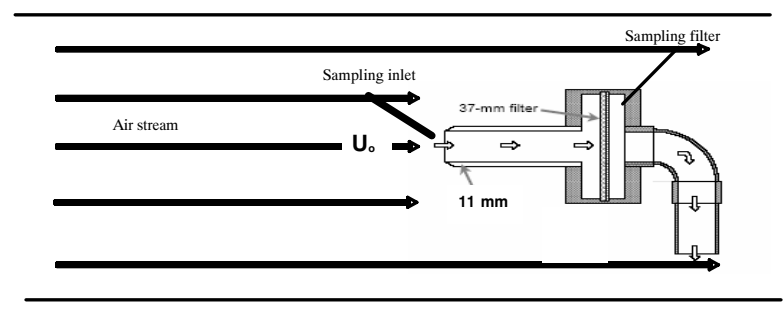

Isokinetic Sampling $\mathbf{U}_{\mathrm{o}}=\mathbf{U}$

Figure 4. Schematic diagram of a dust sampler with 11-mm probe inlet diameter and a $37-\mathrm{mm}$ filter assembly. $U_{0}$ is the mean free stream velocity and $U$ is the average air velocity through the sampling probe.

SKC, Eighty Four, Pa.) were conditioned by placing them in the oven for $24 \mathrm{~h}$ at $103^{\circ} \mathrm{C}$ before and after sampling. Filter conditioning was done to minimize the effect of humidity and collected water droplets on filter weights. All filters were weighed in an electronic microbalance (model AG245, Mettler-Toledo, Hightstown, N.J.) with a sensitivity of $0.01 \mathrm{mg}$.

The effectiveness of the EPWS was determined by comparing the dust concentrations at the inlet and exhaust of the scrubber. The EPWS dust removal efficiency $(\eta)$ was calculated using the following equation:

$$
\eta=\frac{C_{i}-C_{o}}{C_{i}} \times 100
$$

where $\mathrm{C}_{\mathrm{i}}$ is the mean dust mass concentration at the scrubber inlet and $\mathrm{C}_{0}$ is the mean dust mass concentration at the scrubber exhaust. The mean $\eta$ values were analyzed statistically by using PROC GLM of SAS (Version 9.1, SAS Institute, Inc., Cary, N.C.). Treatment means were compared at a level of significance of $5 \%$.

\section{Field Evaluation}

The prototype EPWS was field evaluated at a swine finishing building at Kansas State University, Manhattan, Kansas. The mechanically-ventilated barn is $34 \mathrm{~m}$ long, $12 \mathrm{~m}$ wide, and $2.5 \mathrm{~m}$ high. There are two double-rows of animal pens, with alleys located centrally and along each wall, and containing a total of 80 pens arranged in four rows. Each pen $(1.6 \times 1.6 \mathrm{~m})$ has a feeder and drinker and, at the time of measurements, each pen had two animals for a total of 160 animals.

The EPWS was installed near the center of the building (fig. 5). The evaluation compared the following cases: (1) EPWS with negatively-charged water spray (i.e., negatively-charged EPWS); (2) wet scrubber with uncharged-water spray (i.e., uncharged scrubber); and (3) fan

Table 3. Relationship among the fan speed setting, mean scrubber outlet airflow rate, and sampling flow rate.

\begin{tabular}{ccc}
\hline $\begin{array}{c}\text { Fan Speed } \\
\text { Setting }\end{array}$ & $\begin{array}{c}\text { Scrubber Outlet Duct Average } \\
\text { Airflow Rate }\left(\mathrm{m}^{3} / \mathrm{min}\right)\end{array}$ & $\begin{array}{c}\text { Sampling Flow } \\
\text { Rate[a] }(\mathrm{L} / \mathrm{min})\end{array}$ \\
\hline 0.25 & 6.4 & 4.0 \\
0.50 & 11.0 & 6.8 \\
0.75 & 17.9 & 10.8 \\
1.00 & 25.4 & 14.8 \\
\hline
\end{tabular}

[a] Sampling flow rate was based on the mean air velocity at the sampling point. 

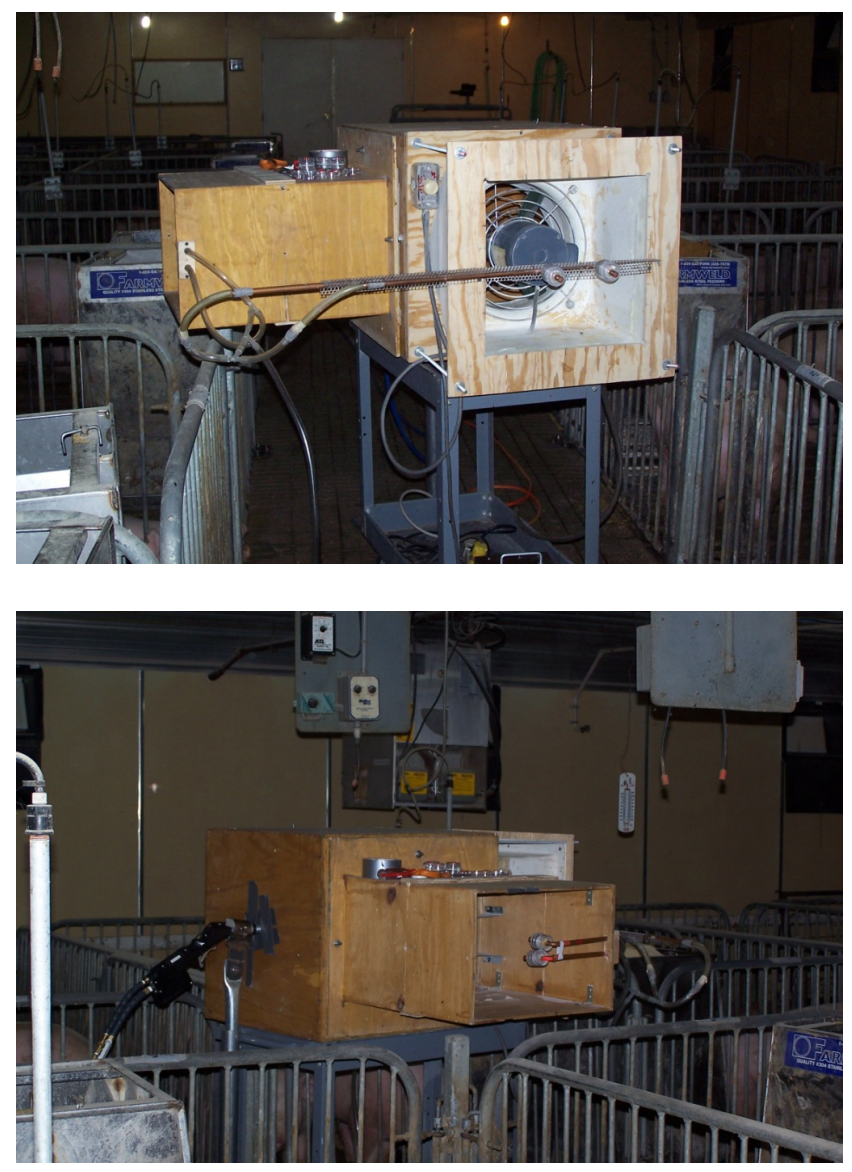

Figure 5. Photographs showing the scrubber inside the swine building during testing.

with no water spray (i.e., control). Based upon laboratory results, for all cases the air flow rate was fixed at $11 \mathrm{~m}^{3} / \mathrm{min}$. Table 4 and figure 6 summarize the test conditions in the swine building during the field evaluation. Similar to the laboratory evaluation, the effectiveness of the device was evaluated by measuring the dust mass concentrations upstream and downstream of the device. The $\eta$ value was calculated using equation 1 and the mean $\eta$ values were analyzed statistically using PROC GLM of SAS (Version 9.1, SAS Institute, Inc., Cary, N.C.).

\section{RESULTS AND DisCUSSION}

\section{LABORATORY EVALUATION}

Figure 7 summarizes the effect of air flow rate on the efficiency of the negatively-charged EPWS for corn starch. In general, the mean $\eta$ value increased with decreasing air flow rate from $32 \%$ when the mean air flow rate was

Table 4. Measured parameters inside the swine building during the testing period.

\begin{tabular}{lc}
\hline Parameter & Mean \\
\hline Dust mass concentration $\left(\mathrm{mg} / \mathrm{m}^{3}\right)$ & 0.77 \\
Temperature $\left({ }^{\circ} \mathrm{C}\right)$ & 24.5 \\
Relative humidity $(\%)$ & 55.6 \\
Net charge-to-mass ratio of airborne particles $(\mathrm{mC} / \mathrm{kg})$ & +0.68 \\
Geometric mean diameter of particles $(\mu \mathrm{m})$ & 9.34 \\
Geometric standard deviation of particles & 2.11 \\
\hline
\end{tabular}

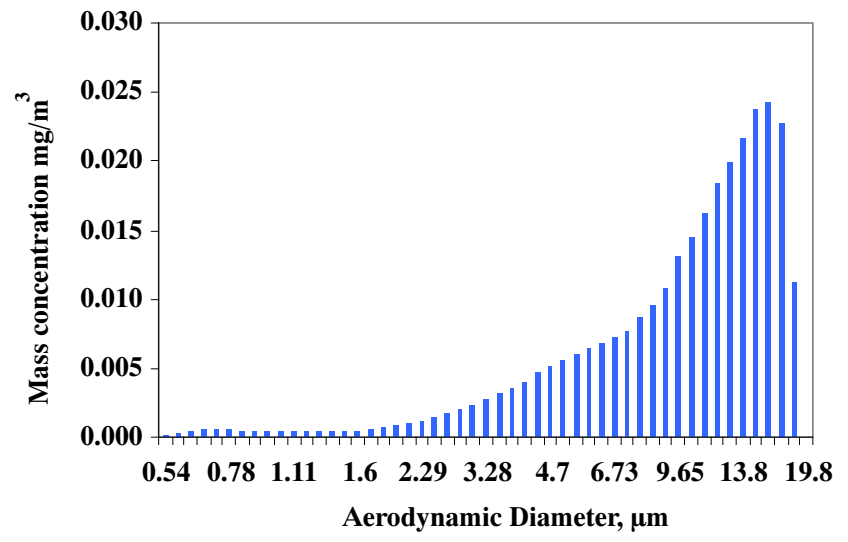

Figure 6. Measured particle size distribution inside the building based on mass concentration, average of 360 samples.

$25.4 \mathrm{~m}^{3} / \mathrm{min}$ (i.e., full fan speed setting) to $79 \%$ when the mean air flow rate was $6.37 \mathrm{~m}^{3} / \mathrm{min}$. The increase in mean $\eta$ values with decreasing air flow rate could be due to the decrease in the loss of water droplets (e.g., by evaporation) and consequently, more collisions between the charged water droplets and the particles with decreasing air flow rate. In general, the lifetime of a droplet depends on various factors, including temperature, humidity, droplet diameter, air velocity, among others. For example, on the basis at which vapor can diffuse away from the droplet, the lifetime of a $30-\mu \mathrm{m}$ droplet evaporating at normal temperature and a relative humidity of about $55 \%$ is approximately $2.6 \mathrm{~s}$ (Hinds, 1999). Increased air velocity around the droplet will increase the mass diffusion and thermal conduction at the droplet surface and, consequently, the rate of evaporation of the droplet. These results suggest that there is an optimum ratio between the air flow rate and the amount of water spray for each specific mixing volume that controls the residence time and increases collection surfaces which results in higher collection of particles by the water droplets. An air flow rate of $11 \mathrm{~m}^{3} / \mathrm{min}$ was then used throughout remainder of the study.

Grounding the inner surface of the mixing chamber (fig. 1) did not significantly improve the effectiveness of the EPWS for corn starch. For the negatively-charged EPWS, the

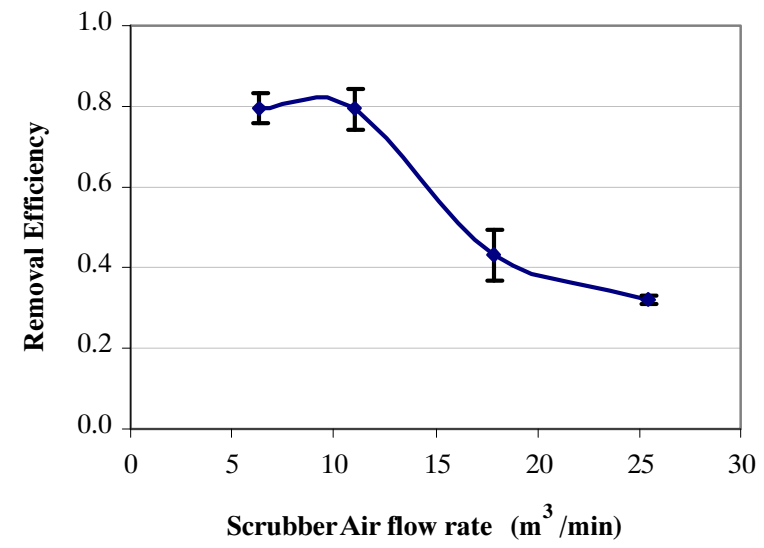

Figure 7. Effect of EPWS air flow rate on the removal efficiency of the negatively charged EPWS for corn starch. Error bars represent standard deviation. Each data point represents the mean of three replicates. 
mean $\eta$ values were $67.9 \%(\mathrm{SD}=7.4 \%$ ) for the grounded case and $78.6 \%(\mathrm{SD}=5.22 \%)$ for the ungrounded case. For the positively-charged EPWS, on the other hand, the mean $\eta$ values were $67.8 \%(\mathrm{SD}=11.8 \%)$ with grounding and $73 \%$ $(\mathrm{SD}=4.60 \%)$ for the ungrounded case. For the subsequent tests, the mixing chamber was not grounded.

Table 5 summarizes the mean $\eta$ values for corn starch for the negatively-charged EPWS, uncharged scrubber, and control. The negatively-charged EPWS had significantly $(\mathrm{P}<0.05)$ greater mean $\eta$ value $(78.6 \%)$ than either the control $(\eta=20.9 \%)$ or the uncharged wet scrubber $(\eta=57.7 \%)$. Also, the uncharged wet scrubber had significantly $(\mathrm{P}<0.05)$ greater mean $\eta$ value than the control. The mechanisms for particle removal of water droplets (charged or uncharged) are relatively well understood (Mathai, 1983). When an uncharged water droplet approaches a cloud of particles with a relative velocity, particles may directly collide with the droplet (i.e., collection by inertial impaction), barely touch the droplet (i.e., collection by interception), or entirely miss the droplet (i.e., particle is not collected). As such, it is expected that the uncharged scrubber would be more effective than the control (i.e., no water droplets) in removing particles because of the capture of particles by the water droplets. When the water droplets are highly charged, as in the EPWS, electrostatic forces enhance the capture of the dust particles by the water droplets (Law and Giles, 2009), resulting in improvement in overall collection efficiency of the droplets, as was the case in this study.

Table 5 also shows that the spray charge polarity did not significantly affect the mean $\eta$ values of the EPWS either for corn starch or $\mathrm{NaHCO}_{3}$. Corn starch and $\mathrm{NaHCO}_{3}$ had slightly different net charge-to-mass ratios, as measured with the Faraday cage sampler (Almuhanna, 2007). For example, when dispersed into the experimental chamber, corn starch particles had a slightly negative net charge-to-mass ratio of $-0.11(\mathrm{SD}=0.07) \mathrm{mC} \mathrm{kg}^{-1} ; \mathrm{NaHCO}_{3}$, on the other hand, had a slightly positive net charge-to-mass ratio of +0.20 $(\mathrm{SD}=0.001) \mathrm{mC} \mathrm{kg}^{-1}$.

Comparison of corn starch and $\mathrm{NaHCO}_{3}$ shows that the mean $\eta$ value was greater for corn starch than for $\mathrm{NaHCO}_{3}$ (table 5). This could be due to the difference in size between the two particles. Based on measurement with an Aerodynamic Particle Sizer ${ }^{\circledR M}$ spectrometer, $\mathrm{NaHCO}_{3}$ had a mean geometric mean diameter (GMD) of $6.1 \mu \mathrm{m}$ and a geometric standard deviation (GSD) of 2.2; corn starch, on the other hand, had a mean GMD of $13.1 \mu \mathrm{m}$ and a mean GSD of 1.4 (table 2). Even with enhanced electrostatic effects, smaller particles tend to be more difficult to capture than larger particles.

\section{Field Evaluation}

Table 6 summarizes the mean $\eta$ values for the prototype EPWS in the swine building. Similar to the laboratory evaluation, the negatively-charged EPWS was significantly more effective in removing dust particles $(\eta=70.3 \%)$ than either the uncharged scrubber $(\eta=46.2 \%)$ or the control (i.e., only fan was operated) $(\eta=17.1 \%)$. With only the fan, removal of particles was likely due primarily to impaction of particles to surfaces and to each other. With uncharged droplets, removal of particles was enhanced by capture of particles by the water droplets. With highly charged water droplets as collection surfaces, electrostatic forces could have enhanced the capture of the dust particles.

Comparison of the laboratory and field evaluations, however, indicated that the mean $\eta$ value for the EPWS was slightly smaller in the swine building $(\eta=70.3 \%)$ than in the experimental chamber for corn starch $(\eta=78.6 \%)$. The lower mean $\eta$ value could be due to differences in concentration and size distribution between the particles in the swine building and the test particles used in the laboratory evaluation. For example, the concentration was smaller in the swine building than in the chamber $\left(<1 \mathrm{mg} / \mathrm{m}^{3}\right.$ for the swine building and $>5 \mathrm{mg} / \mathrm{m}^{3}$ for the experimental chamber). With smaller concentration in the swine building, collisions between the water droplets and the particles are expected to be lower, resulting in smaller removal efficiency. In addition, the mean GMD of the particles in the swine building when the EPWS was being tested was $9.34 \mu \mathrm{m}$, which was smaller than that of corn starch. Again, smaller particles are more difficult to remove than larger particles, even with electrostatic forces. For $\mathrm{NaHCO}_{3}$, on the other hand, the mean $\eta$ value for the EPWS in the swine building $(70.3 \%)$ was considerably higher than that for the EPWS in the chamber with $\mathrm{NaHCO}_{3}$ $(55.1 \%)$. The smaller size of $\mathrm{NaHCO}_{3}$ particles compared to those in the swine building can also explain the smaller removal efficiency for $\mathrm{NaHCO}_{3}$ in the experimental chamber.

Table 6. Field dust-removal efficiencies (mass basis) of the EPWS
for operation with charged water spray, uncharged for operation with charged water spray, and fan only.
water spent

\begin{tabular}{|c|c|c|c|}
\hline \multirow[b]{2}{*}{ Treatment } & \multicolumn{2}{|c|}{$\begin{array}{l}\text { Removal } \\
\text { Efficiency }\end{array}$} & \multirow{2}{*}{$\begin{array}{c}\text { No. } \\
\text { of Reps }\end{array}$} \\
\hline & Mean $^{[\mathrm{a}]}$ & $\mathrm{SD}$ & \\
\hline Negatively-charged EPWS & $70.3 \mathrm{a}$ & 8.7 & 4 \\
\hline Uncharged scrubber & $44.6 \mathrm{~b}$ & 5.9 & 3 \\
\hline Control (i.e., only the fan was operated) & $17.1 \mathrm{c}$ & 9.7 & 4 \\
\hline
\end{tabular}

Table 5. Laboratory dust-removal efficiencies (mass basis) of the EPWS for operation with charged water spray, uncharged water spray, and fan only.

\begin{tabular}{|c|c|c|c|c|c|c|}
\hline \multirow[b]{2}{*}{ Treatment } & \multicolumn{3}{|c|}{ Corn Starch } & \multicolumn{3}{|c|}{$\mathrm{NaHCO}_{3}$} \\
\hline & Mean[a] & SD & No. of Reps & Mean[a] & SD & No. of Reps \\
\hline Negatively-charged EPWS & $78.6 \mathrm{a}$ & 5.22 & 6 & $55.1 \mathrm{a}$ & 13.1 & 4 \\
\hline Positively-charged EPWS & $73.0 \mathrm{a}$ & 4.60 & 3 & $68.0 \mathrm{a}$ & 4.6 & 3 \\
\hline Uncharged scrubber & $57.7 \mathrm{~b}$ & 3.67 & 3 & $23.9 b$ & 13.7 & 3 \\
\hline Control (i.e., only the fan was operated) & $20.9 \mathrm{c}$ & 3.04 & 3 & - & - & \\
\hline
\end{tabular}

[a] Column means followed by the same letter are not significantly different at $95 \%$ level of confidence. 
It should be noted that the prototype EPWS tested in this study was designed to have only one spray nozzle. Other potential designs, with different number of nozzles, sizes, etc., are possible depending on the application and size of the livestock building. Future work is needed to optimize the design and further enhance the performance of the EPWS. For example, more spray nozzles can be used to increase the removal efficiency. In addition, there is a need to examine the potential of the EPWS as exhaust air cleaner system.

\section{CONCLUSIONS}

A prototype electrostatically assisted particulate wet scrubber (EPWS) was developed and tested under both laboratory and field conditions. The following conclusions were drawn from this research:

- The EPWS had significantly greater particle removal efficiency than either the control (i.e., no water spray) or the uncharged wet scrubber. The efficiency was affected by the type of particle; the device was generally more effective in removing corn starch (generally larger) than $\mathrm{NaHCO}_{3}$ particles (smaller).

- Under laboratory conditions, the negatively-charged EPWS did not significantly differ from the positively-charged EPWS in terms of removal efficiency.

- Under laboratory conditions, the removal efficiency decreased as the EPWS air flow rate increased.

In general, the EPWS proved to be effective in reducing airborne dust concentration under both controlled laboratory conditions and field conditions. Future work will involve refining the design of the scrubber (e.g., modifying the size and geometry).

\section{ACKNOWLEDGEMENTS}

This research is supported in part by the Kansas Agricultural Experiment Station, Manhattan, Kansas, and King Faisal University, Hofuf, Saudi Arabia. The authors acknowledge the technical support of Mr. Darrell Oard, Ms. Edna Razote, Ms. Li Guo, Ms. Susana Castro Pjesky, and Dr. Mark Casada.

\section{REFERENCES}

Almuhanna, E. 2007. Dust control in livestock buildings with electrostatically charged water spray. Ph.D. dissertation. Manhattan, Kans.: Kansas State University.

Almuhanna, E., R. G. Maghirang, J. P. Murphy, and L. E. Erickson. 2008. Effectiveness of electrostatically charged water spray in reducing dust concentration in enclosed spaces. Trans. ASABE 51(1): 279-286.
ASTM Standards. 1997. D 4470-97. Standard test methods for static electrification. Philadelphia, Pa.: ASTM.

Donham, K. J., P. Haglind, Y. Peterson, R. Rylander, and L. Belin. 1989. Environmental and health studies of workers in Swedish swine confinement buildings. Br J. Ind. Med. 46(1): 31-37.

Dosman, J. A., B. L. Graham, D. Hall, P. Pahwa, H. H. McDuffie, M. Lucewicz, and T. To. 1988. Respiratory symptoms and alterations in pulmonary function tests in swine producers in Saskatchewan: Results of a survey of farmers. J. Occup. Med. 30(9): 715-720.

Hassler, H., and E. Birgitta. 1978. A new method for dust separation using autogenous electrically charged fog. J. Powder \& Bulk Solids Tech. 2(1): 10-14.

Hinds, W. C. 1999. Aerosol Technology: Properties, Behavior, and Measurement of Airborne Particles, 2nd ed. New York: John Wiley \& Sons.

Law, S. E. 1978. Embedded-electrode electrostatic-induction spray-charging nozzle: Theoretical and engineering design. Trans. ASAE 21(6): 1096-1104.

Law, S. E. 2001. Agricultural electrostatic spray application: A review of significant research and development during the 20 th century. J. Electrostat. 51(1): 25-42.

Law, S. E., and D. K. Giles. 2009. Electrostatic abatement of airborne respirable dust emission from mechanized tree-nut harvesting: theoretical basis. J. Electrostat. 67(2-3): 84-88.

Lear, C. W., W. F. Krieve, and E. Cohen. 1975. Charged droplet scrubbing for fine particle control. J. Air Pollut. Control Assoc. 25(2): 184-189.

Licht, L. A., and R. Miner. 1979. A scrubber to reduce livestock confinement building odors. Trans. ASAE 22(5): 11521156.

Mathai, C. V. 1983. Charged fog technology: Part II. Prototype tests of a new charged fog generator for fugitive emission control. $J$. Air Pollut. Control Assoc. 33(8): 756759.

Predicala, B. Z., and R. G. Maghirang. 2004. Measurement of particulate matter emission rates from mechanically ventilated swine barns. Trans. ASAE 47(2): 557565.

Senthilselvan, A., J. A. Dosman, S. P. Kirychuk, E. M. Barber, C. S. Rhodes, Y. Zhang, and T. Hurst. 1997a. Accelerated lung function decline in confinement swine building workers. Chest 111(6): 17331741.

Senthilselvan, A., Y. Zhang, J. A. Dosman, E. M. Barber, S. P. Kirychuk, C. S. Rhodes, and T. Hurst. 1997b. Positive human effects of dust suppression with canola oil in swine barns. Am.J. Respir. Crit. Care Med. 156(2): 410417.

Zejda, J. E., T. S. Hurst, C. S. Rhodes, E. M. Barber, H. H. McDuffie, and J. A. Dosman. 1993. Respiratory health of swine producers, focus on young workers. Chest 103(3): 702709.

Zejda, J. E., E. M. Barber, J. A. Dosman, S. A. Olenchock, H. H. McDuffie, C. S. Rhodes, and T. S. Hurst. 1994. Respiratory health status in swine producers relates to endotoxin exposure in the presence of low dust levels. J. Occup. Med. 36(1): 4956.

Zhang, Y., A. Tanaka, J. A. Dosman, A. Senthilselvan, E. M. Barber, S. Kirychuk, and T. Hurst. 1998. Acute respiratory responses of human subjects to air quality in a swine building. $J$. Agric. Eng. Res. 70(4): 367373. 